\title{
CRP, WBC and monocyte/lymphocyte ratio relation as a preoperative predictive factor for adhesions observed during laparoscopic cholecystectomy
}

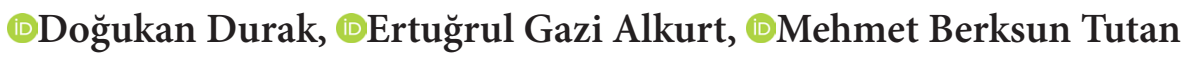 \\ Çorum Erol Olçok Training and Research Hospital, General Surgery Clinic, Çorum, Turkey
}

Cite this article as: Durak D, Alkurt EG, Tutan MB. CRP, WBC and monocyte/lymphocyte ratio relation as a preoperative predictive factor for adhesions observed during laparoscopic cholecystectomy. J Health Sci Med 2021; 4(5): 686-691.

\begin{abstract}
Aim: The purpose of this study to predict adhesion related technical difficulties during operation by comparing preoperative CRP, WBC, Monocyte/Lymphocyte ratio (Mo/Ly) and intra-operative adhesion findings.

Material and Method: This was a retrospective study. This study includes 116 elective and emergency cholelithiasis cases whose operation performed at Çorum Erol Olçok Training and Research Hospital in 2020 and 2021. Adhesions on gallbladder were graded during operation and divided into two groups. Groups graded based on intra-operative findings were compared with preoperative CRP, WBC, and monocyte/lymphocyte ratio.

Results: The patients were divided into two groups based on the adhesion grade as Grade 1-2 (n=84) and Grade 3-4 ( $\mathrm{n}=32)$. Mean WBC count of Grade 3-4 group was mean $11.05 \pm 4.4510^{9} / \mathrm{L}$ and this value was statistically significantly higher $(\mathrm{p}=0.01)$ than Grade 1-2 group. Mean CRP value of Grade 3-4 group was found as $50.91 \pm 77.25 \mathrm{mg} / \mathrm{L}$ and this value was significantly elevated $(\mathrm{p}<0.001)$ when compared with Grade 1-2 group. Mean monocyte/lymphocyte ratio was found as $0.29 \pm 0.18$ and $0.52 \pm 0.33$ for Grade 1-2 and Grade 3-4 groups, respectively and these values were found statistically significant $(\mathrm{p}<0.001)$. Adhesions were significantly higher for CRP $(>24.5 \mathrm{mg} / \mathrm{l})$, WBC $\left(>11.5510^{9} / \mathrm{L}\right)$, monocyte/lymphocyte ratio $(>0.2693)$ cut-off values.
\end{abstract}

Conclusion: Preoperative estimation of adhesion grade helps the surgeon considerably. This study shows that high CRP, WBC, and Mo/Ly ratio values can help the estimation of intensity of adhesions and challenges during operation.

Keywords: Cholecystectomy, intra-operative adhesion, C-reactive protein, white blood cell, monocyte/lymphocyte ratio

\section{INTRODUCTION}

Laparoscopic cholecystectomy (LC) is considered golden standard all over the world for the treatment of cholelithiasis (1).

LC can be used both for cholelithiasis cases and also for cases with acute cholecystitis. Adhesions developed as a result of inflammations and fibrosis in acute cholecystitis cases may cause difficulties during cholecystectomy. In these cases, there is risk of converting to open cholecystectomy.

Inflammation and fibrosis can be observed both in elective cholelithiasis and also in acute cholecystitis cases. Certain technical difficulties may arise during operation due to this inflammation and fibrosis. In these cases, it becomes difficult to discern anatomy, to dissect Calot's triangle, and uncontrolled bleeding and biliary tract injury may occur. Studies have shown that these factors are effective in conversion from laparoscopic cholecystectomy to open cholecystectomy (2).

CRP (C-reactive protein), procalcitonin, WBC (white blood cell) values are elevated in inflammation cases. Studies have shown that procalcitonin values higher than $1.5 \mathrm{ng} / \mathrm{ml}$ is a predictive value for difficult cholecystectomy (3). Furthermore, studies have shown that CRP value is the best inflammation marker to identify severity of acute cholecystitis and conversion to open cholecystectomy during operation (4).

The purpose of this study to predict technical difficulties during operation by comparing preoperative CRP, WBC, Monocyte/Lymphocyte ratio and intra-operative adhesion findings. 


\section{MATERIAL AND METHOD}

Ethical approval was obtained from the Hitit University Non-interventional Clinical Research Ethics Committee (Date: 30.04.2021, Decision No: 2021-66). All procedures were carried out in accordance with the ethical rules and the principles of the Declaration of Helsinki.

This study includes 116 elective and emergency cholelithiasis cases whose operation performed at Corum Erol Olcok Training and Research Hospital in 2020 and 2021. All patients with their ages over 18 and who had undergone laparoscopic cholecystectomy by Members of Gastroenterology Surgery Subspeciality of Department of General Surgery between February 2020 and April 2021 were included in this study, and their data were collected from Hospital Data Management System retrospectively. Hospitals with ages under 18 and conversion cholecystectomy cases were excluded in this study. All cases were laparoscopically operated on by a single expert surgeon.

Data included in this study are age, gender, admission complaint, diagnosis, white blood cell count (WBC), monocyte count (MO), lymphocyte count (LY), platelet count (PLT), serum C-reactive protein level (CRP), additional diseases, emergency level of operation at the time of their admission, and time from admission to operation, operation duration, intra-operative adhesion grade, necessity to place drain and post-operative complication status. Monocyte and lymphocyte values and Monocyte/Lymphocyte ratio (MO/LY) were calculated and included as well.

Findings observed intra-operatively were graded by a single expert surgeon and recorded. Grades are defined as, Grade 1: No adhesion; Grade 2: light adhesion, peritoneal adipose tissue allowing easy dissection; Grade 3: chronic pericholecystitis and pericholecystic fibrosis, dissection is hard but anatomy can be traced; Grade 4: duodenum, colon adhesion to gallbladder causing anatomic distortion along with gallbladder wall thickening which does not allow safe dissection(5).

Patients were divided into two groups as Group 1: Grade 1-2 $(n=84)$ and Group 2: Grade 3-4 $(n=32)$ based on their intra-operative adhesion grades. WBC, CRP, MO/LY ratio, PLT and other parameters were compared between the groups in order to identify operation difficulty level.

Blood was drawn from patients preoperatively and laboratory tests were conducted on the samples. CRP, $\mathrm{WBC}$ and $\mathrm{MO} / \mathrm{LY}$ ratios were recorded. Cholelithiasis status of each patient was confirmed via preoperative ultrasonography.

Groups graded based on intra-operative findings were compared with CRP, WBC and monocyte/lymphocyte ratio.

\section{Statistical Analyses}

Descriptive statistics such as age, gender, number of additional diseases were presented as number and percentage for categorical variables, and as mean \pm standard deviation or median (minimummaximum) based on the data distribution for quantitative variables. Normal distribution of data was assessed with Shapiro Wilks test. Based on the distribution of the data, paired sampling t-test (Student's t-test) or MannWhitney $\mathrm{U}$ test was utilized for independent two groups and ANOVA or Kruskal-Wallis test was employed for more than two groups for the comparison of quantitative variables with the sociodemographic properties and research groups. Relationship between quantitative variables was investigated with Pearson or Spearman correlation coefficient based on data distribution. Ratio comparisons or correlation tests based on research groups were performed with Chi-square or Fisher exact test. Level of statistical significance was selected as $\mathrm{p}<0.05$. Statistical analyses were performed by using IBM SPSS Statistics for Windows software (Version 26, IBM Corp., Armonk, N.Y., USA).

\section{RESULTS}

Out of total of 116 patients, 30 of them were male (25.9\%) and 86 of them were female (74.1\%). Age mean of entire patient group was found as $51.21 \pm 15.35$ where median was 50.5, and youngest and oldest patients were 21 and 81 years old, respectively. In terms of additional diseases, $74(63 \%)$ of the patients had no foreknown additional disease whereas 34 patients $(29.3 \%)$ had 1 systemic disease and 8 patients $(6.9 \%)$ had 2 systemic diseases.

The clinical features of the patients, comorbidities, grading of intraoperative adhesions, WBC, CRP, MO/ LY mean, mean operation times and complications are summarized in Table 1.

Pre-operative and post-operative parameters were compared for the patients divided into two groups based on the adhesion grade as Grade 1-2 $(n=84)$ and Grade 3-4 $(\mathrm{n}=32)$.

Most of the Group 1 patients with light adhesion were asymptomatic at the time of visit (71.4\%), whereas abdominal pain was statistically significant for Group 2 patients $(\mathrm{p}<0.001)$ where adhesions were considerably higher. While cholelithiasis diagnosis was frequent in Grade 1-2 group patients (73.8\%), cholecystitis diagnosis was more frequent in Grade 3-4 patients (75\%) (Table 2).

Mean white blood cell count of Grade 3-4 group was mean $11.05 \pm 4.45109 / \mathrm{L}$ and this value was statistically 
significantly higher $(\mathrm{p}=0.01)$ than the mean value of Grade 1-2 group, which was found as $8.43 \pm 2.7710^{9} / \mathrm{L}$. Similarly, mean C-reactive protein value of Grade 3-4 group was found as $50.91 \pm 77.25 \mathrm{mg} / \mathrm{L}$ and this value was significantly elevated $(\mathrm{p}<0.001)$ when compared with the mean values of Grade 1-2 group, which was found as $10.98 \pm 35.37 \mathrm{mg} / \mathrm{L}$. Lymphocyte count was identified as $1.99 \pm 0.5710^{9} / \mathrm{L}$ for Grade $1-2$ group and $1.48 \pm 0.7010^{9} / \mathrm{L}$ for Grade 3-4 group and difference was statistically significantly identified $(\mathrm{p}<0.001)$ (Table 2). Monocyte count was found as $0.63 \pm 0.24109 / \mathrm{L}$ and $0.53 \pm 0.2010^{9} / \mathrm{L}$ for Grade 3-4 and Grade 1-2, respectively, and the difference, although high, was not statistically significant $(\mathrm{p}=0.055)$ (Table 2$)$. Mean monocyte/lymphocyte ratio was found as $0.29 \pm 0.18$ and 0.52 \pm 0.33 for Grade 1-2 and Grade 3-4 groups, respectively and these values were found statistically significant $(\mathrm{p}<0.001)$ (Table 2$)$.

Operations were statistically significantly longer with 14 minutes longer for cases with high adhesion

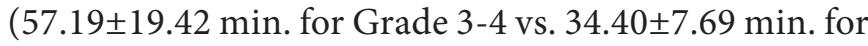
Grade 1-2, p<0.001).

Adhesions were more frequent at emergency operations, however, there was no relation between duration until operation and observation of adhesions $(\mathrm{p}<0.001$ and $\mathrm{p}=0.522$, respectively).

\begin{tabular}{|c|c|c|}
\hline \multicolumn{3}{|c|}{ Entire Group $(n=116)$} \\
\hline \multirow{2}{*}{ Gender } & Male & $30(25.9 \%)$ \\
\hline & Female & $86(74.1 \%)$ \\
\hline \multicolumn{2}{|l|}{ Age } & $51.21 \pm 15.35(50.50)$ \\
\hline \multirow{3}{*}{$\begin{array}{l}\text { Number of } \\
\text { Additional } \\
\text { Disease }\end{array}$} & 0 & $74(63 \%)$ \\
\hline & 1 & $34(29.3 \%)$ \\
\hline & 2 & $8(6.9 \%)$ \\
\hline \multirow{3}{*}{ Complaint } & Asymptomatic & $66(56.9 \%)$ \\
\hline & Abdominal Pain & $48(41.4 \%)$ \\
\hline & Hepatitis & $2(1.7 \%)$ \\
\hline \multirow{4}{*}{ Diagnosis } & cholelithiasis & $66(56.9 \%)$ \\
\hline & cholecystitis & $38(32.8 \%)$ \\
\hline & Post-cholecystitis & $4(3.4 \%)$ \\
\hline & Pancreatitis & $8(6.9 \%)$ \\
\hline \multicolumn{2}{|l|}{ WBC } & $9.15 \pm 3.50(8.00)$ \\
\hline \multicolumn{2}{|l|}{ CRP } & $21.99 \pm 53.23(3.42)$ \\
\hline \multicolumn{2}{|l|}{ MO } & $0.56 \pm 0.22(0.52)$ \\
\hline \multicolumn{2}{|l|}{ LY } & $1.86 \pm 0.65(1.93)$ \\
\hline \multicolumn{2}{|l|}{ PLT } & $258.93 \pm 63.75(245)$ \\
\hline \multicolumn{2}{|c|}{$\mathrm{MO} / \mathrm{LY}$} & $0.36 \pm 0.25(0.25)$ \\
\hline \multicolumn{2}{|c|}{ Operation Duration } & $40.69 \pm 15.78(35)$ \\
\hline \multicolumn{2}{|c|}{ Number of Open Surgery } & $44(37.9 \%)$ \\
\hline \multicolumn{2}{|c|}{ Duration Until Emergency Operation } & $3.45 \pm 1.48(3)$ \\
\hline \multirow{4}{*}{$\begin{array}{l}\text { Intra-operative } \\
\text { Grade }\end{array}$} & 1 & $58(50 \%)$ \\
\hline & 2 & $26(22.4 \%)$ \\
\hline & 3 & $16(13.8 \%)$ \\
\hline & 4 & $16(13.8 \%)$ \\
\hline \multicolumn{2}{|c|}{ Necessity to place Drain } & $68(58.6 \%)$ \\
\hline \multicolumn{2}{|c|}{ Complication } & $6(5.2 \%)$ \\
\hline
\end{tabular}
White blood cell count (WBC), monocyte count (MO), lymphocyte count (LY), platelet
count (PLT), serum C-reactive protein (CRP), Monocyte/Lymphocyte ratio (MO/LY)

Table 2. Comparison of Grade 1-2 and Grade 3-4 Groups

\begin{tabular}{|c|c|c|c|c|}
\hline \multicolumn{5}{|c|}{ Entire Group $(n=116)$} \\
\hline \multirow{2}{*}{ Gender } & Male & $18(21.4 \%)$ & $12(37.5 \%)$ & \multirow[b]{2}{*}{$\mathrm{p}=0.77$} \\
\hline & Female & $66(78.6 \%)$ & $20(62.5 \%)$ & \\
\hline Age & & $48.02 \pm 13.98(46.50)$ & $59.56 \pm 15.86(63)$ & $\mathrm{p}<0.001$ \\
\hline \multirow{3}{*}{$\begin{array}{l}\text { Number of } \\
\text { additional } \\
\text { disease }\end{array}$} & 0 & $64(76.2 \%)$ & $10(31.3 \%)$ & \multirow{3}{*}{$\mathrm{p}<0.001$} \\
\hline & 1 & $18(21.4 \%)$ & $16(50 \%)$ & \\
\hline & 2 & $2(2.4 \%)$ & $6(18.8 \%)$ & \\
\hline \multirow{3}{*}{ Complaint } & Asymptomatic & $60(71.4 \%)$ & $6(18.8 \%)$ & \multirow{3}{*}{$\mathrm{p}<0.001$} \\
\hline & Abdominal pain & $22(26.2 \%)$ & $26(81.3 \%)$ & \\
\hline & Hepatitis & $2(2.4 \%)$ & $0(0 \%)$ & \\
\hline \multirow{4}{*}{ Diagnosis } & cholelithiasis & $62(73.8 \%)$ & $4(12.5 \%)$ & \multirow{4}{*}{$\mathrm{p}<0.001$} \\
\hline & cholecystitis & $14(16.7 \%)$ & $24(75 \%)$ & \\
\hline & Post-cholecystitis & $2(2.4 \%)$ & $2(6.3 \%)$ & \\
\hline & Pancreatitis & $6(7.1 \%)$ & $2(6.3 \%)$ & \\
\hline \multicolumn{2}{|l|}{ WBC } & $8.43 \pm 2.77(7.70)$ & $11.05 \pm 4.45(10.06)$ & $\mathrm{p}=0.01$ \\
\hline \multicolumn{2}{|l|}{ CRP } & $10.98 \pm 35.37(3.13)$ & $50.91 \pm 77.25(16.50)$ & $\mathrm{p}<0.001$ \\
\hline \multicolumn{2}{|l|}{ MO } & $0.53 \pm 0.20(0.50)$ & $0.63 \pm 0.24(0.62)$ & $\mathrm{p}=0.055$ \\
\hline \multicolumn{2}{|l|}{ LY } & $1.99 \pm 0.57(2)$ & $1.49 \pm 0.70(1.35)$ & $\mathrm{p}<0.001$ \\
\hline \multicolumn{2}{|l|}{ PLT } & $266.90 \pm 66.89(248)$ & $238.00 \pm 49.71(240.50)$ & $\mathrm{p}=0.073$ \\
\hline \multicolumn{2}{|c|}{$\mathrm{MO} / \mathrm{LY}$} & $0.29 \pm 0.18(0.22)$ & $0.52 \pm 0.33(0.42)$ & $\mathrm{p}<0.001$ \\
\hline \multicolumn{2}{|c|}{ Operation duration } & $34.40 \pm 7.69(35)$ & $57.19 \pm 19.42(47.50)$ & $\mathrm{p}<0.001$ \\
\hline \multicolumn{2}{|c|}{ Number of open surgery } & $18(21.4 \%)$ & $26(81.3 \%)$ & $\mathrm{p}<0.001$ \\
\hline \multicolumn{2}{|c|}{ Duration until emergency operation } & $3.22 \pm 1.43(3)(\mathrm{n}=18)$ & $3.62 \pm 1.52(3)(\mathrm{n}=26)$ & $\mathrm{p}=0.522$ \\
\hline \multicolumn{2}{|c|}{ Necessity to place drain } & $36(42.9 \%)$ & $32(100 \%)$ & $\mathrm{p}<0.001$ \\
\hline \multicolumn{2}{|c|}{ Complication } & $2(2.4 \%)$ & $4(12.5 \%)$ & $\mathrm{p}=0.28$ \\
\hline
\end{tabular}


Although drain was required to be placed to all of the patients with high adhesion grade was observed, only 36 of the patient (42.9\%) of Grade 1-2 group were required drain placement $(\mathrm{p}<0.001)$. Number of complications were not statistically significant between groups $(\mathrm{p}=0.28)$. Since $\mathrm{MO} / \mathrm{LY}$ ratio was statistically significantly different between groups, ROC analysis was performed in order to distinguish adhesion grades and area under the curve was calculated. Cutoff value sensitive and specific for differentiation of $\mathrm{MO} / \mathrm{LY}$ ratio for the two groups was identified as 0.2693 with $81 \%$ sensitivity and $64 \%$ specificity $(\mathrm{p}<0.001)$.

Positive and negative predictive values were found as $46 \%$ and $90 \%$. Performed risk analysis have shown that $\mathrm{MO} / \mathrm{LY}$ value higher than 0.2693 have increased observation of adhesion 680\% (OR 7.80 95\% CI 2.88821.067, p <0.001) (Figure 1) (Table 3) (Table 4).

As for WBC, $12.5510^{9} / \mathrm{L}$ value was 43.8 sensitive and 92.9\% specific, and positive and negative predictive values were calculated as $70 \%$ and $81.3 \%$, respectively. WBC values higher than $12.5510^{9} / \mathrm{L}$ have increase observation of adhesion 911\% (OR $10.111 \% 95$ CI 3.416-29.924, p<0.001) (Figure 1) (Table 3) (Table 4).

Cut-off value of $24.5 \mathrm{mg} / \mathrm{L}$ calculated for CRP value have shown to explain adhesion with $50 \%$ sensitivity and 97\% specifity. Positive and negative predictive values were found as $88 \%$ and $83.7 \%$. CRP values higher than $24.5 \mathrm{mg} / \mathrm{L}$ have increase observation of adhesion $4100 \%$ (95\% CI 8.577-195.998, p <0.001) (Figure 1) (Table 3) (Table 4).

Table 3. Distribution of groups based on cut-off value

\begin{tabular}{|lcccc|}
\hline \multirow{2}{*}{$\begin{array}{l}\text { Inflammatory } \\
\text { marker }\end{array}$} & $\begin{array}{c}\text { Cut-off } \\
\text { value }\end{array}$ & $\begin{array}{c}\text { Grade 1-2 } \\
(\mathbf{n}=\mathbf{8 4})\end{array}$ & $\begin{array}{c}\text { Grade 3-4 } \\
(\mathbf{n}=32)\end{array}$ & $\begin{array}{c}\text { Statistical } \\
\text { significance }\end{array}$ \\
\hline $\mathrm{MO} / \mathrm{LY}$ & $<0.2693$ & $54(64.3 \%)$ & $6(18.8 \%)$ & \\
& $\geq 0.2693$ & $30(35.7 \%)$ & $26(81.2 \%)$ & $\mathrm{p}<0.001$ \\
$\mathrm{WBC}$ & $<12.55$ & $78(92.9 \%)$ & $18(56.3 \%)$ & \\
& $\geq 12.55$ & $6(7.1 \%)$ & $14(43.8 \%)$ & $\mathrm{p}<0.001$ \\
$\mathrm{CRP}$ & $<24.5$ & $82(97.6 \%)$ & $16(50 \%)$ & \\
& $\geq 24.5$ & $2(2.4 \%)$ & $16(50 \%)$ & $\mathrm{p}<0.001$ \\
\hline $\begin{array}{l}\text { White blood cell count }(\mathrm{WBC}) \text {, serum C-reactive protein (CRP), Monocyte/ } \\
\text { Lymphocyte ratio (MO/LY) }\end{array}$ & & \\
\hline
\end{tabular}

\section{DISCUSSION}

Laparoscopic cholecystectomy has become golden standard both in elective cholelithiasis and also in acute cholecystitis cases. Operation would be harder especially in acute cholecystitis cases due to certain risk factors. However, as suggested at Tokyo Guideline 2018, laparoscopic cholecystectomy is the primary method of treatment in acute cholecystitis cases as well (6). Certain factors which causes gallbladder operation to be more difficult and causes conversion to cholecystectomy. Lipman et al. (7) Stated these factors as male gender, high WBC value, low albumin value, diabetic patient, pericholecystic fluid on ultrasonography, and high bilirubin value. Kama et al. (8), on the other hand, added previous surgery, acute cholecystitis, and increased gallbladder wall thickness on ultrasonography.

Operation is more difficult in acute cholecystitis cases than elective cholelithiasis cases. The main reason for this is difficult. visualization of anatomy due to intraabdominal and perihepatic adhesions, and difficulty in dissection of Calot's triangle (5). The number of patients operated on due to acute cholecystitis was significantly higher in the group with higher grade of adhesion in our study as well.

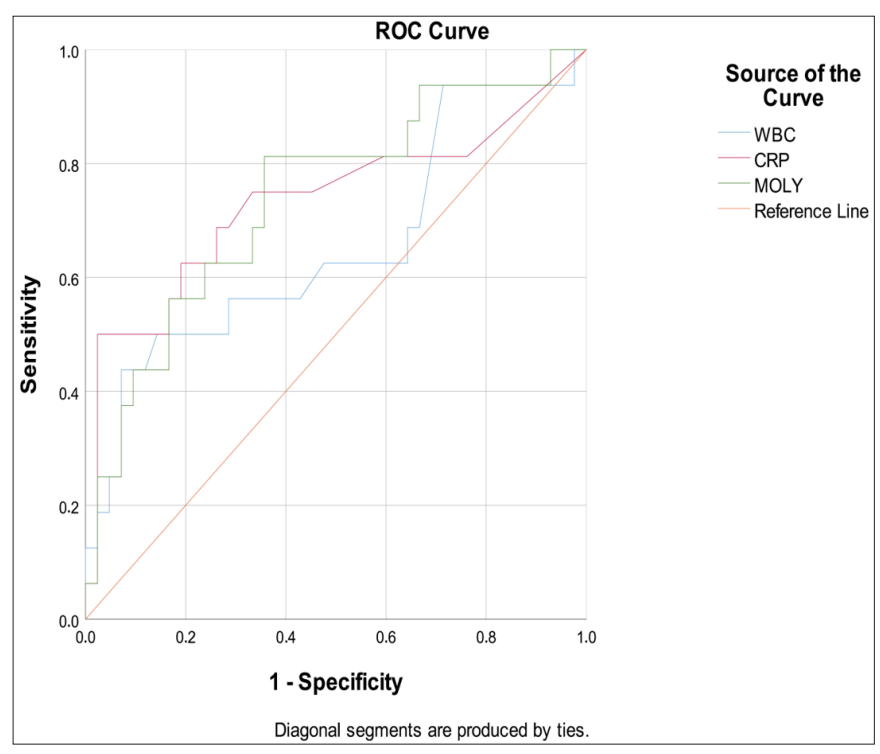

Figure 1. Diagonal segments are produced by ties.

Table 4. Diagnostic values and Odds Ratios of Markers

\begin{tabular}{|c|c|c|c|c|c|c|c|c|c|c|c|}
\hline \multirow[b]{2}{*}{$\begin{array}{l}\text { Inflam } \\
\text { matory } \\
\text { marker }\end{array}$} & \multirow[b]{2}{*}{ Cut-off } & \multirow[b]{2}{*}{ Sensitivity } & \multirow[b]{2}{*}{ Specifity } & \multirow[b]{2}{*}{ PPV } & \multirow[b]{2}{*}{ NPV } & \multicolumn{3}{|c|}{ ROC Analysis } & \multicolumn{3}{|c|}{ Odds Ratio } \\
\hline & & & & & & Alan (SE) & \%95 CI & p (ROC) & OR & 95\% CI & $\mathrm{p}(\mathrm{OR})$ \\
\hline CRP & 24.500 & 0.500 & 0.970 & 0.889 & 0.837 & $0.734(0.061)$ & $0.614-0.853$ & $<0.001$ & 41.000 & $8.577-195.998$ & $<0.001$ \\
\hline $\mathrm{MO} / \mathrm{LY}$ & 0.269 & 0.813 & 0.643 & 0.464 & 0.900 & $0.740(0.054)$ & $0.635-0.845$ & $<0.001$ & 7.800 & $2.888-21.067$ & $<0.001$ \\
\hline WBC & 12.550 & 0.438 & 0.929 & 0.700 & 0.813 & $0.654(0.062)$ & $0.532-0.776$ & 0.011 & 10.111 & $3.416-29.924$ & $<0.001$ \\
\hline
\end{tabular}


According to Lee et al. (9), old age is a predictive variable in difficult cholecystectomy. In our study, it was observed that elderly were grouped in higher adhesion group (Group 2) and therefore their operations were more difficult (G3-4:59.56 \pm 15.86 min. vs G1-2:48.02 \pm 13.98 min., $\mathrm{p}<0.001)$.

Studies have shown that elevated WBC is correlated with increase in acute cholecystitis and post-operative complications (10). Furthermore, elevated WBC is correlated with the severity of acute cholecystitis (6). However, no data could be identified in the literature regarding relationship between elevated WBC and gallbladder adhesions. In our study, WBC was identified to be statistically significantly higher in Grade 3-4 higher adhesions. Furthermore, the cut-off calculation have yielded $12.5510^{9} / \mathrm{L}$ value with $43.8 \%$ sensitivity and $92.9 \%$ specifity. Analyses have shown that WBC values higher than $12.5510^{9} / \mathrm{L}$ increases observation of adhesions on gallbladder $911 \%$.

Similarly, CRP values higher than $30 \mathrm{~g} / \mathrm{L}$ is considered to be a criteria for acute cholecystitis according to Tokyo Guidelines. However, according to Tokyo Guidelines, CRP value is not a criteria that identifies severity of acute cholecystitis. On the contrary, Beliaev et al. (11) considered CRP level as an important factor in identification of severity. Diaz-Flores et al. have mentioned that CRP values higher than $110 \mathrm{~g} / \mathrm{L}$ is correlated with difficult laparoscopic cholecystectomy. Multivariant analyses conducted by Tianchong Wu et al. (12) concluded that CRP value is an effective factor in prediction of difficult laparoscopic cholecystectomy. In our study, CRP value was found to be statistically significantly higher $(\mathrm{p}<0.001)$ in highly adhesive group of Grade 3-4. Cutoff value of $24.5 \mathrm{mg} / \mathrm{L}$ calculated for CRP value have shown to explain adhesion with 50\% sensitivity and $97 \%$ specifity. CRP value higher than 24.5 $\mathrm{mg} / \mathrm{L}$ increases encountering intraoperative adhesion frequency $4100 \%$ (95\% CI 8.577-195.998). This indicates that pre-operative CRP values higher than this cut-off value indicates a difficult laparoscopic cholecystectomy may occur.

Study conducted by Micic et al. found a relation between increasing neutrophile/lymphocyte ratio (NLR) and acute cholecystitis. This study reported that estimating NLR value higher than 4.18 pre-operatively is important to predict difficult cholecystectomy (13). The study conducted by Ahmed et al. (14) concludes that cases with NLR values higher than 5 had longer and more difficult cholecystectomy operation. The study conducted by Lee et al. (7) have concluded that high NLR values were observed in acute cholecystitis cases higher than chronic cholecystitis and mortality was observed more in cases with NLR values higher than 3 . In our study, sensitive and specific Monocyte/lymphocyte ratio (Mo/Ly) cut-off value to differentiate the two groups was found as 0.2693 with $81 \%$ sensitivity and $64 \%$ specifity. Mo/Ly ratio higher than 0.2693 have increase observation of adhesion 911\%. Furthermore, mean monocyte/lymphocyte ratio was found as $0.29 \pm 0.18$ and $0.52 \pm 0.33$ for Grade $1-2$ and Grade 3-4 groups, respectively and these values were found statistically significant $(\mathrm{p}<0.001)$. Therefore, it can be predicted that cholelithiasis cases with Mo/Ly ratio higher than this cut-off value may cause operation to be more difficult due to advanced adhesions.

\section{CONCLUSION}

Adhesions on gallbladder, either acute cholecystitis or elective cholelithiasis, causes operation to be more difficult during laparoscopic cholecystectomy. Preoperative estimation of adhesion grade helps the surgeon considerably. This study shows that high CRP, $\mathrm{WBC}$ and $\mathrm{Mo} / \mathrm{Ly}$ ratio values can help the estimation of intensity of adhesions and challenges during operation. We believe that this study shall pave way to more comprehensive studies in the future.

\section{ETHICAL DECLARATIONS}

Ethics Committee Approval: Ethical approval was obtained from the Hitit University Non-interventional Clinical Research Ethics Committee (Date: 30.04.2021, Decision No: 2021-66).

Informed Consent: All patients signed the free and informed consent form.

\section{Referee Evaluation Process: Externally peer-reviewed.}

Conflict of Interest Statement: The authors have no conflicts of interest to declare.

Financial Disclosure: The authors declared that this study had received no financial support.

Author Contributions: All of the authors declare that they have all participated in the design, execution, and analysis of the paper and approved the final version.

Acknowledgment: A part of this study was presented as an oral presentation at the 9th Turkey Ekmud Scientific Platform on May 22, 2021.

\section{REFERENCES}

1. Navez, B, Prevention of bile duct injury (BDI) during cholecystectomy. Acta Chir Belg 2003; 103: 151-3.

2. Bingener-Casey, J, Richards ML, Strodel WE, Schwesinger WH, Sinirik KR. Reasons for conversion from laparoscopic to open cholecystectomy: a 10-year review. J Gastrointest Surg 2002; 6: 800-5.

3. Tianchong W, Minjun L, Yuehua G, Jiangang B, Yusheng G, Shiyun B. Role of procalcitonin as a predictor in difficult laparoscopic cholecystectomy for acute cholecystitis case: A retrospective study based on the TG18 criteria Observational Study Sci Rep 2019; 9: 10976. 
4. Mahdi B, Slim Z, Bassem K, et al. C-reactive protein is the best biomarker to predict advanced acute cholecystitis and conversion to open surgery. a prospective cohort study of 556 cases. J Gastrointest Surg 2020; 24: 2766-72.

5. Ercan, M, Bostanci EB, Teke Z, et al. Predictive factors for conversion to open surgery in patients undergoing elective laparoscopic colecystectomy. J Laparoendosc Adv Surg Tech A 2010; 20: 427-34.

6. Wakabayashi, G, Iwashita Y, Hibi T, et al. Tokyo Guidelines 2018: surgical management of acute cholecystitis: safe steps in laparoscopic cholecystectomy for acute cholecystitis (with videos). J Hepatobiliary Pancreat Sci 2018; 25: 73-86.

7. Lipman JM, Claridge JA, Haridas M, et al., Preoperative findings predict conversion from laparoscopic to open cholecystectomy. Surgery 2007; 142: 556-63.

8. Kama NA, Doganay M, Dolapci M, Reis E, Atli, Kologlu M. Risk factors resulting in conversion of laparoscopic cholecystectomy to open surgery. Surg Endosc 2001; 15: 965-8.

9. Lee NW, Collins J, Britt R, Britt LD. Evaluation of preoperative risk factors for converting laparoscopic to open cholecystectomy. Am Surg 2012; 78: 831-3.

10. Agrawal N, Singh S, Khichy S. Preoperative prediction of difficult laparoscopic cholecystectomy: a scoring method. Niger J Surg 2015; 21: 130-3.

11. Beliaev A, Booth M. C-reactive protein as a diagnostic and prognostic marker for acute cholecystitis and safety conversion of laparoscopic cholecystectomy, in Advances in Medicine and Biology, Vol 101, L.V. Berhardt, Editor 2016, Nova Science Publishers. p. 15-37.

12. Wu T, Luo M, Guo Y, Bi J, Guo Y, Bao S. Role of procalcitonin as a predictor in difficult laparoscopic cholecystectomy for acute cholecystitis case: A retrospective study based on the TG18 criteria. Sci Rep 2019; 9: 10976.

13. Micic D, Stankovic S, Lalic N, Dukic V, Polovina S. Prognostic Value of Preoperative Neutrophil-to-lymphocyte Ratio for Prediction of Severe Cholecystitis. J Med Biochem 2018; 37: 1217.

14. Ahmed SE, Rehman S, Edilbe M,Jonker L, Canelo R. Can neutrophil-lymphocyte ratio predict operators' difficulty in early cholecystectomies; a retrospective cohort study. Ann Emerg Surg 2017; 2: 1016 